\title{
ON THE VARIATION AND ABUNDANCE OF SIREX NITIDUS HARRIS
}

\author{
By ChaRles W. JoHnson
}

\section{Boston Society of Natural History}

Dr. Frederic T. Lewis has obtained a large and interesting series of a horntail referable to Sirex nitidus Harris, at his summer place at Randolph, N. H. On July 29, 1930, Dr. Lewis sent me 18 males and 5 females; on August 3, 24 males and 25 females; on August 7, 9 males and 17 females; on August 10, 5 males and 4 females; on August 22 to 29, 6 males and 15 females; in all, 62 males and 68 females, a total of 130. Having but one male and three females of this species after twenty-six years collecting in New England, this large number came as a great surprise. The series is especially interesting in showing a remarkable range of variation. The smallest male measures $13 \mathrm{~mm}$., the largest $25 \mathrm{~mm}$., and the smallest female is $12 \mathrm{~mm}$. and the largest $24 \mathrm{~mm}$. This measurement does not include the ovipositor. Between the two extremes there is a complete gradation in size. There is also a great variation in the color of the two sexes, which together with the problem of distribution make the species of the genus Sirex difficult to define.

In determining this species there are many obstacles. It does not agree with $S$. cyaneus Fabr. as defined by either Bradley $^{1}$ or Waterston ${ }^{2}$, but is closer to $S$. noctilio Fabr. as redescribed by Waterston. It differs, however, from that species in having all the femora of the male bright yellow not "darkened," the posterior tibiæ and the first three joints of the tarsi black. The female has the same form of cornus and length of ovipostor as S. noctilio, but

${ }^{1}$ J. C. Bradley, Journ. Ent. and Zool., vol. 5, p. 19, 1913.

${ }^{2}$ James Waterston, Bull. Ent. Research, vol. 5, p. 221, 1928. 
the "tergites II-VIII" are not "dull black," but of a deep blue color, smooth and highly polished, as described by Harris $^{3}$ under Urocerus nitidus.

The type came from Dublin, N. H., near Mt. Monadnock, about one hundred miles south of Randolph. It seems evident that this is the prevailing form of this region and that it represents the $S$. nitidus Harris. I have also received a male from Mr. Dwight Blaney, who collected it on Ironbound Island near Bar Harbor, Maine. The males vary considerably in color. Three and often four of the basal segments and the eighth segment of the abdomen are dark blue. One has the base of the eighth only narrowly bluish, and a second specimen has the same segment with only a narrow apical margin of yellow. Many specimens have on the three or four yellow segments dorsal spots of blue, and the seventh segment is often widely margined with blue. As in S. noctilio the first transverse brachial vein may be either complete or incomplete, but this character is of little value. In 100 specimens, 60 had the vein complete and in 40 it was incomplete; in addition two specimens had the vein complete in one wing and incomplete in the other.

The specimens came from a Balsam fir (Abies balsamea) which had been cut down during the summer of 1929. On September $3 \mathrm{Dr}$. Lewis sent a section of the tree 11 inches long, with a diameter of $43 / 4$ inches, from which 41 specimens had emerged. With the Sirex nitidus were taken three males of Ibalia ensiger Nort. This species like I. maculipennis Hald. is probably parasitic on Sirex and other wood borers.

While collecting on Nantucket, Mass., Sept. 9, 1929, I obtained an interesting specimen associated with Sirex edwardsii, a male in which all except the first and second segments of the abdomen are yellow. If the third and fourth joints of the antennæ were not reddish I should be inclined to refer it to S. nigricornis without question, and perhaps this may prove to be the case. All of the many male specimens of $S$. edwardsii taken have only the fifth and sixth segments of the abdomen yellow.

${ }^{3} \mathrm{~T}$. W. Harris. Insects of Massachusetts Injurious to Vegetation, p. $391,1841$. 

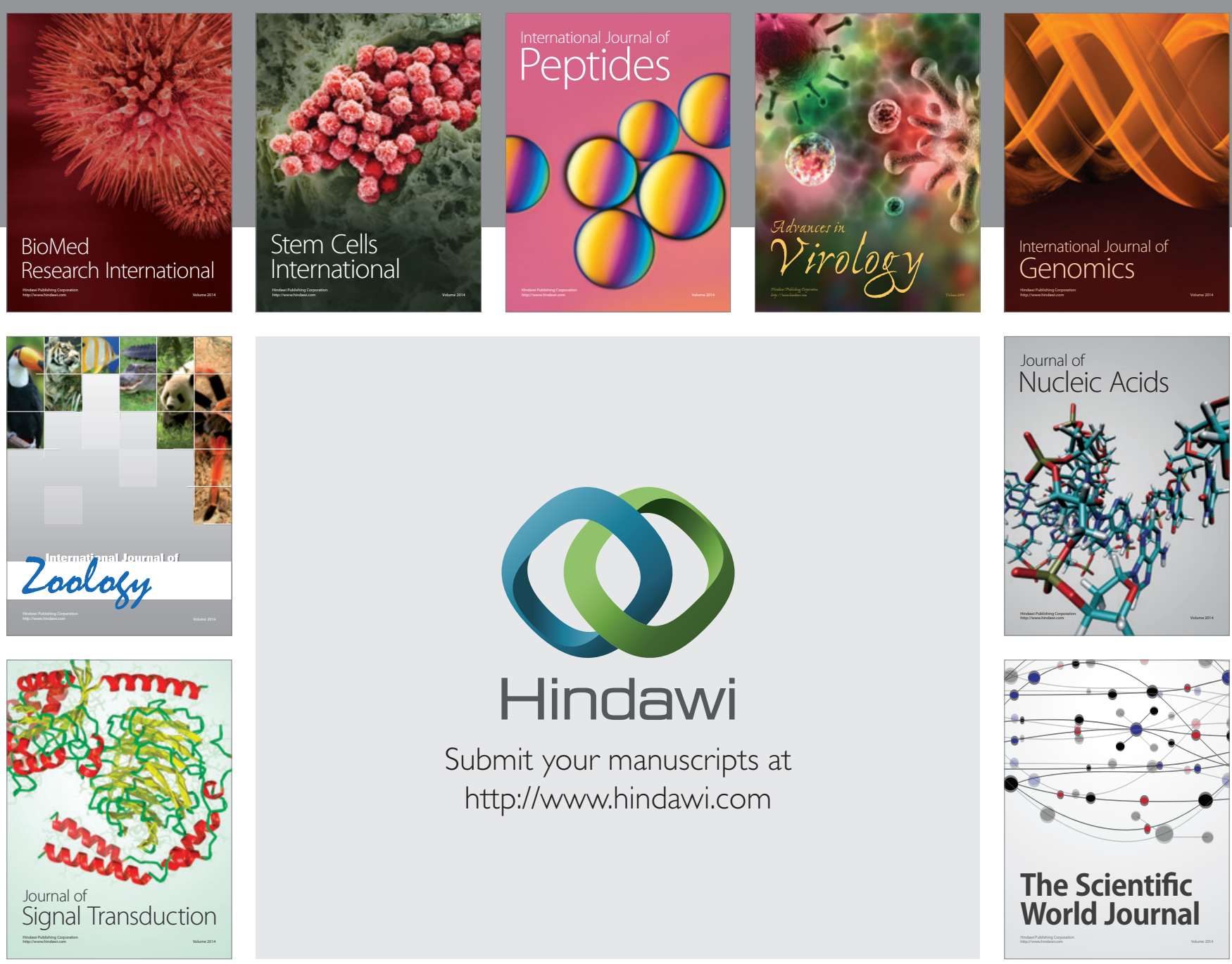

Submit your manuscripts at

http://www.hindawi.com
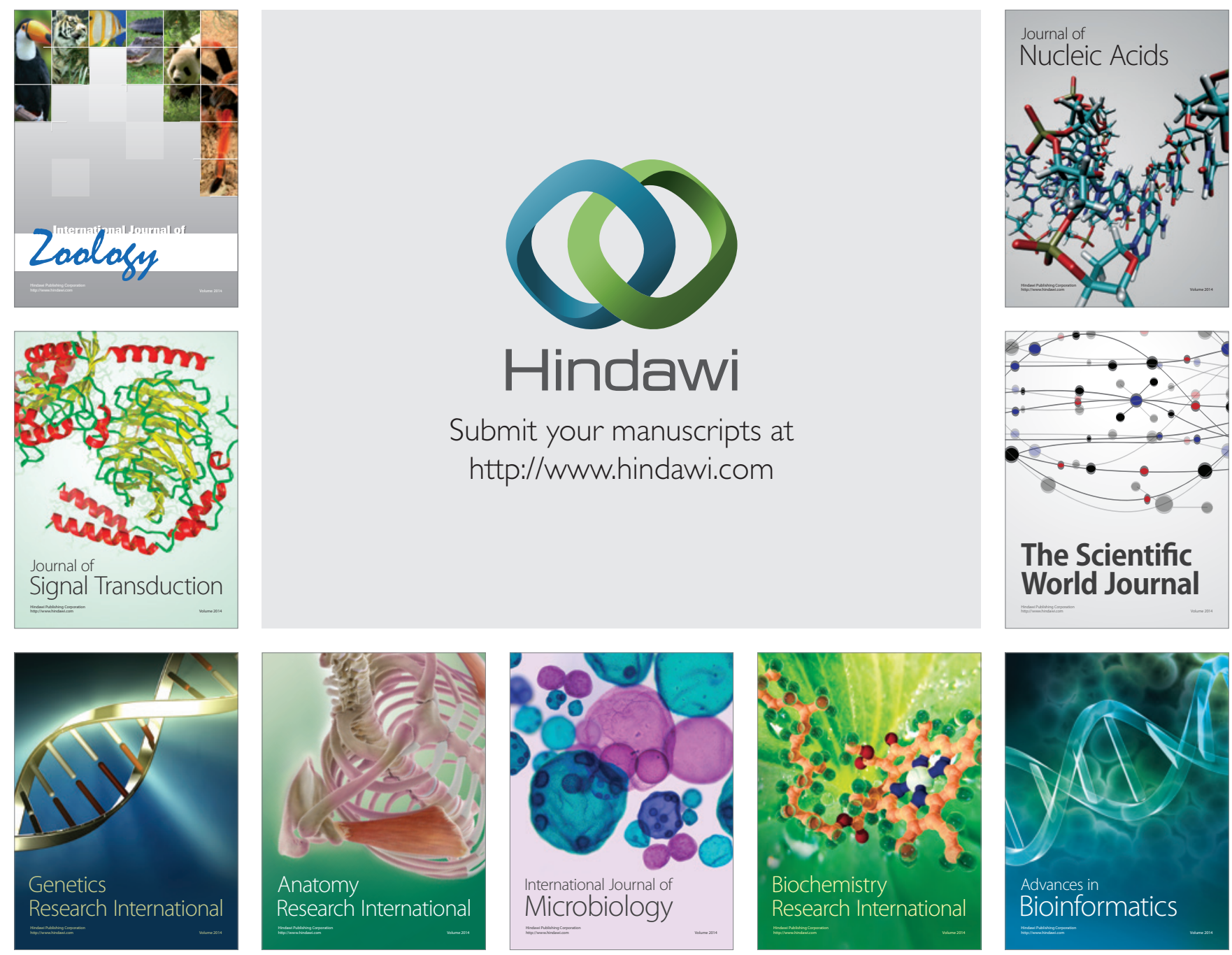

The Scientific World Journal
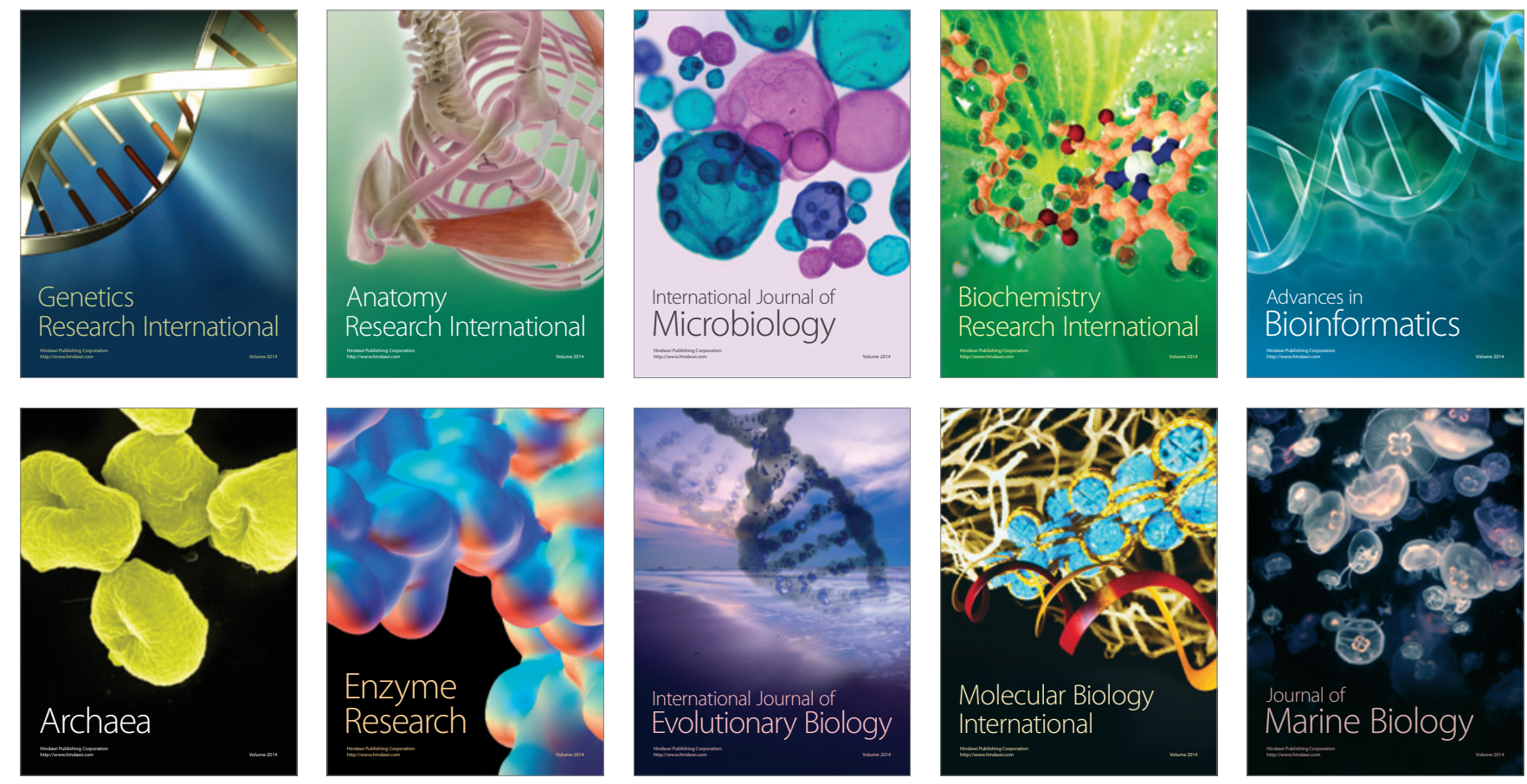